\title{
Knowledge, Attitude and Practice towards Exclusive Breastfeeding among Mothers in Pokhara-Lekhnath
}

\author{
Gurung $\mathrm{R}^{1^{*}}$, Silwal $\mathrm{M}^{2}$, Gurung $\mathrm{A}^{1}$, Sah $\mathrm{I}^{1}$, Koirala $\mathrm{D}^{1}$, Paudel $\mathrm{S}^{1}$, Upadhayaya $\mathrm{S}^{1}$ \\ ${ }^{1}$ Lecturer, ${ }^{2}$ Co-ordinator \\ College of Nursing Sciences, Gandaki Medical College, Pokhara, Nepal
}

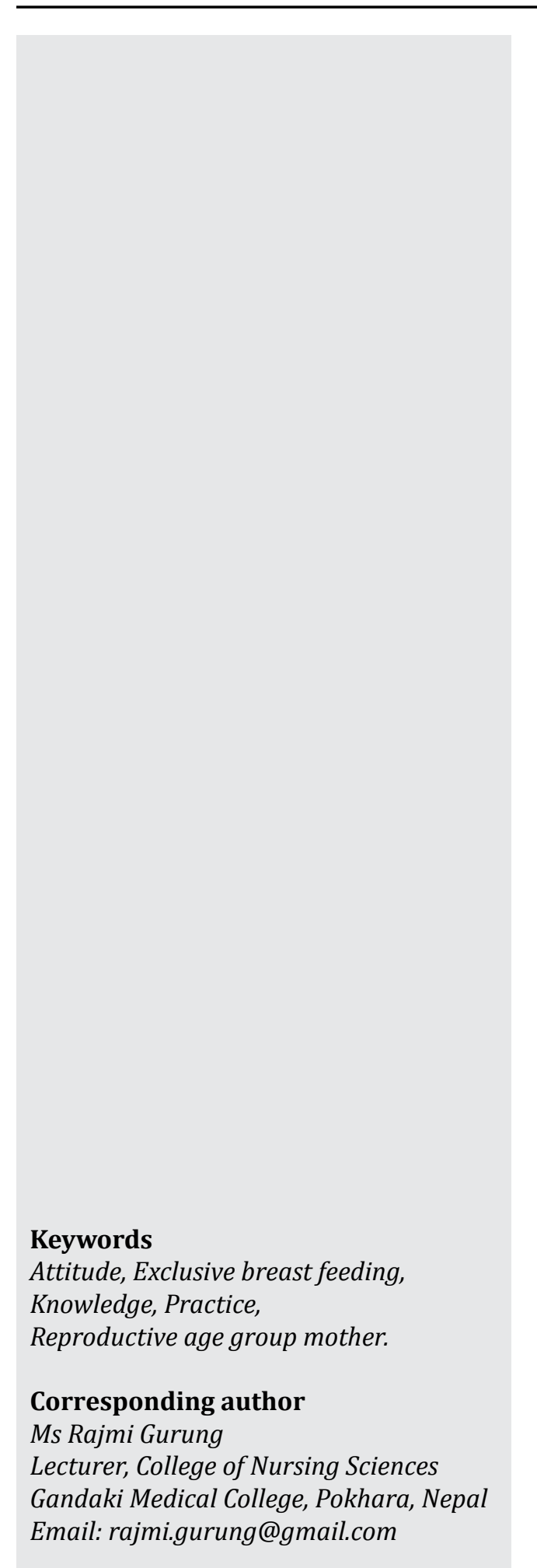

\begin{abstract}
Background: Exclusive breastfeeding means that the infant receives only breast milk. Infants should be exclusively breastfed for the first six months of life to achieve optimal growth, development and health. Thereafter, to meet their evolving nutritional requirements, infants should receive nutritionally adequate and safe complementary foods, while continuing to breastfeed for up to two years or beyond. Breastfeeding is an unequalled way of providing ideal food for the healthy growth and development of infants; it is also an integral part of the reproductive process with important implications for the health of mothers.
\end{abstract}

Objective: To assess the knowledge, attitude and practice of pregnant women on exclusive breastfeeding.

\begin{abstract}
Methods: The quantitative descriptive research design was used for this study. Purposive sampling technique was used to select the subjects in community setting. Total 140 subjects were taken as a sample and self-administered structured questionnaire on knowledge, attitude and practice of exclusive breast feeding among reproductive age group women was used to collect data.
\end{abstract}

Results: The study shows that out of 140 women, 48 (34.3\%) belonged to 26 - 30 age group, 136 (97.14\%) were married, 109 (77.9\%) women followed Hindu caste, 67 (47.9\%) women belonged to Dalit group, 129 (92.1\%) women were housewife, 73 (52.1\%) women had taken primary education, 68 (48.6\%) had monthly income >20000, $116(82.9 \%)$ had $\leq 3$ children. Among 140 women, 69 (49.3\%) had good knowledge and fair knowledge whereas only $2(1.4 \%)$ had poor knowledge. Regarding attitude $122(87.1 \%)$ thought that EBF was better than other artificial feeding, 75 (53.6\%) believed that first milk should be discarded, $108(77.1 \%)$ agreed that EBF is enough for child up to 6 months, 77 (55\%) didn't feel comfortable with extra feeding other than breast milk, 51 (36.4) stated that they were not comfortable because of insufficient amount to meet child's demand, 100 (71.4\%) agreed that child less than six months who is exclusively breastfed were healthier than child who took additional foods. Out of 140 women, 139 (99.3\%) breastfed her last child, 83 (59.3\%) started breastfeeding within $1 \mathrm{hr}$ after delivery, 77 (55\%) breastfed on demand of baby, 91 (65\%) had not given anything before initiating breastfeeding, 25 (17.9\%) had given plain water before breast milk after delivery, 107 (76.4\%) had given breast milk only starting from birth to six months of age. 
Conclusions: The study revealed that there was good level of knowledge and practice among women in the reproductive age group in Pokhara-Lekhnath. Hence the study strongly suggests that there was appropriate level of knowledge about exclusive breast feeding among mother of reproductive age group in Pokhara - Lekhnath which will help in enhancing the growth and development of child.

\section{INTRODUCTION}

Breastfeeding is a natural act, it is also a learned behaviour ${ }^{1}$. Exclusive breastfeeding is defined as giving no other food or drink not even water except breast milk. Infants should be exclusively breastfed which means receiving only breast milk for the first six months of life to achieve optimal growth, development and health. It is an unequalled way of providing ideal food $^{2}$. Breast milk is the ideal food for the healthy growth and development of infants; breastfeeding is also an integral part of the reproductive process with important implications for the health of mothers ${ }^{2}$.

Breast milk is the natural first food for the babies ${ }^{1}$. For the first six months of life, breast milk alone is the ideal nourishment, providing all the nutrients, including vitamins and minerals, an infant needs, meaning no other liquid or food is needed ${ }^{3}$. It continues to provide energy and nutrient up to half or more of a child's nutritional needs during the second half of the first year, and up to one -third during the second year of life ${ }^{1}$.

Breastfeeding helps strengthening the mother-child bond. It not only helps in making the mother-child relation more intimate, but also helps infant to fight diseases ${ }^{4}$. Breast milk carries antibodies from the mother that help combat the disease $\mathrm{e}^{5}$. It protects infant against infectious and chronic diseases. Exclusive breastfeeding reduces infant mortality rate due to common childhood illness such diarrhea or pneumonia, and helps for a quicker recovery during illness ${ }^{1}$. It also stimulates an infant's immune system and response to vaccination ${ }^{6}$.

Breastfeeding is one of the most effective ways to ensure child health and survival. If breastfeeding were scaled up to nearly universal levels, about 820,000 children would be saved every year. Globally, only $40 \%$ of infants under six months of age are exclusively breastfed $^{7}$. It has been estimated that optimal breastfeeding of children under two years of age has the potential to prevent 1.4 million deaths in children under five in the developing world annually ${ }^{8}$.
As a global goal for optimal maternal and child health and nutrition, all women should be enabled to practice exclusive breastfeeding, and all infants should be fed exclusively on breast milk, from birth to six months of age (March 2001) ${ }^{9}$. Breastfeeding is nearly universal in Nepal and the median duration of breast-feeding is long (33 months). But on the contrary to the recommendations of WHO only two-third of children less than six months of age are exclusively breast fed $^{10}$. Hence, this study is planned to get the base line data on knowledge, attitude and practice of exclusive breastfeeding among lactating women. Study explored the relationship among knowledge and practice, knowledge and attitude of exclusive breastfeeding.

\section{METHODS}

This is a quantitative descriptive study done among the reproductive age group mothers in Pokhara-Lekhnath. Purposive sampling technique was used for data collection and data were collected in the community setting with the help of self-administered structured questionnaire on knowledge, attitude and practice of exclusive breast feeding among reproductive age group women. Four part structured questionnaire were developed to cover the entire aspects of study.

Part I: This part included demographic characteristics of the participants: Age, marital status, religion, ethnicity, occupation, education, monthly income and number of children.

Part II: This part included the questionnaire on knowledge of study participants towards exclusive breast feeding.

Part III: This part included the questionnaire on attitude of study participants towards exclusive breast feeding.

Part IV: This part included the questionnaire on practice of study participants towards exclusive breast feeding.

The data collection was started on June 15, 2017 (2074/03/01 B.S.) and the data collection was completed on July 14, 2017 (2074/03/30 B.S.). Consent was taken voluntarily from the participants before the data 
collection procedure with assured confidentiality. Ethical clearance is obtained from institutional review board of GMC. Purposive sampling technique was used for data collection and data were collected in the community setting with the help of self-administered structured questionnaire on knowledge, attitude and practice of exclusive breast feeding among reproductive age group women. SPSS Program version 16.0 was used for entering and tabulating data. Frequency and Percentage was used to analyze socio-demographic characteristics.

Table 1: Frequency and percentage distribution of demographic characteristics $(\mathrm{N}=140)$

\begin{tabular}{|c|c|c|}
\hline Demographic characteristics & Frequency & Percentage \\
\hline \multicolumn{3}{|l|}{ Age ( in years ) } \\
\hline - $\leq 20$ & 19 & $13.6 \%$ \\
\hline - $\quad 21-25$ & 42 & $30 \%$ \\
\hline - $\quad 26-30$ & 48 & $34.3 \%$ \\
\hline - $\quad \geq 31$ & 31 & $22.1 \%$ \\
\hline \multicolumn{3}{|l|}{ Marital status } \\
\hline - $\quad$ Married & 136 & $97.14 \%$ \\
\hline - Widow & 4 & $2.9 \%$ \\
\hline \multicolumn{3}{|l|}{ Religion } \\
\hline - Hindu & 109 & $77.9 \%$ \\
\hline - Christian & 8 & $5.7 \%$ \\
\hline - Buddhist & 21 & $15 \%$ \\
\hline - $\quad$ Others & 2 & $1.4 \%$ \\
\hline \multicolumn{3}{|l|}{ Ethnicity } \\
\hline - Brahmin & 5 & $3.6 \%$ \\
\hline - Chhetri & 14 & $10 \%$ \\
\hline - Janajati & 54 & $38.6 \%$ \\
\hline - Dalit & 67 & $47.9 \%$ \\
\hline \multicolumn{3}{|l|}{ Occupation } \\
\hline - Housewife & 129 & $92.1 \%$ \\
\hline - $\quad$ Service & 3 & $2.1 \%$ \\
\hline - Business & 5 & $3.6 \%$ \\
\hline - Labour & 3 & $2.1 \%$ \\
\hline \multicolumn{3}{|l|}{ Education } \\
\hline - Illiterate & 45 & $32.1 \%$ \\
\hline - Primary & 73 & $52.1 \%$ \\
\hline - Secondary & 19 & $13.6 \%$ \\
\hline - Bachelor and above & 3 & $2.1 \%$ \\
\hline \multicolumn{3}{|l|}{ Monthly income } \\
\hline - $\quad \leq 10000$ & 22 & $15.7 \%$ \\
\hline - $10001-20000$ & 50 & $35.7 \%$ \\
\hline - $\quad>20000$ & 68 & $48.6 \%$ \\
\hline \multicolumn{3}{|l|}{ Number of children } \\
\hline - $\quad \leq 3$ & 116 & $82.9 \%$ \\
\hline - $\quad>3$ & 24 & $17.1 \%$ \\
\hline
\end{tabular}

The above Table shows that out of 140 women, 48 (34.3\%) belonged to 26 - 30 age group, 136 (97.14\%) were married, 109 (77.9\%) women followed Hindu caste, 67 (47.9\%) women belonged to Dalit group, 129 (92.1\%) women were housewife, 73 (52.1\%) women had taken primary education, $68(48.6 \%)$ had monthly income $>20000,116(82.9 \%)$ had $\leq 3$ children.

Fig 1: Knowledge of exclusive breastfeeding $\mathrm{N}=140$

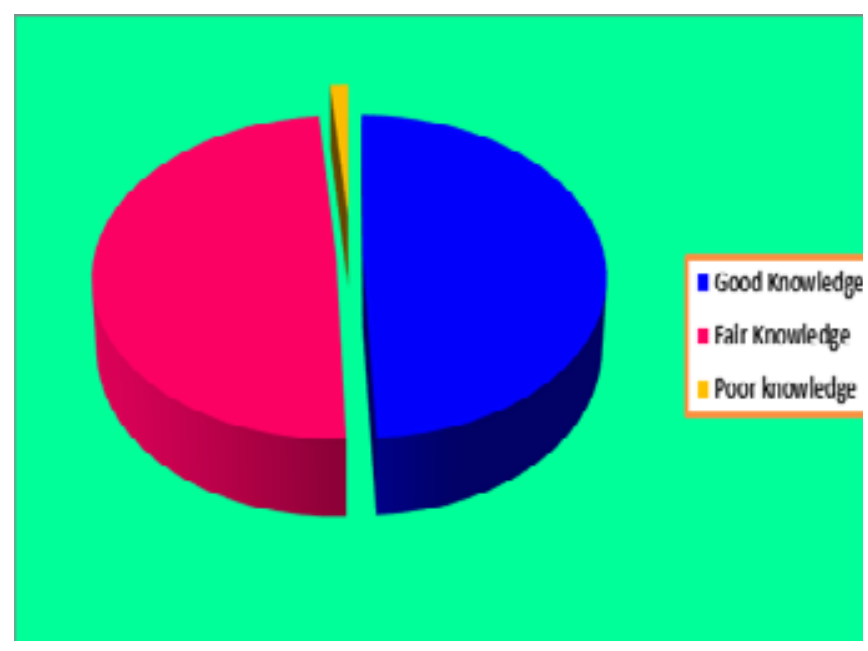

Fig 2: Source of information on exclusive breastfeeding (N $=140$ )

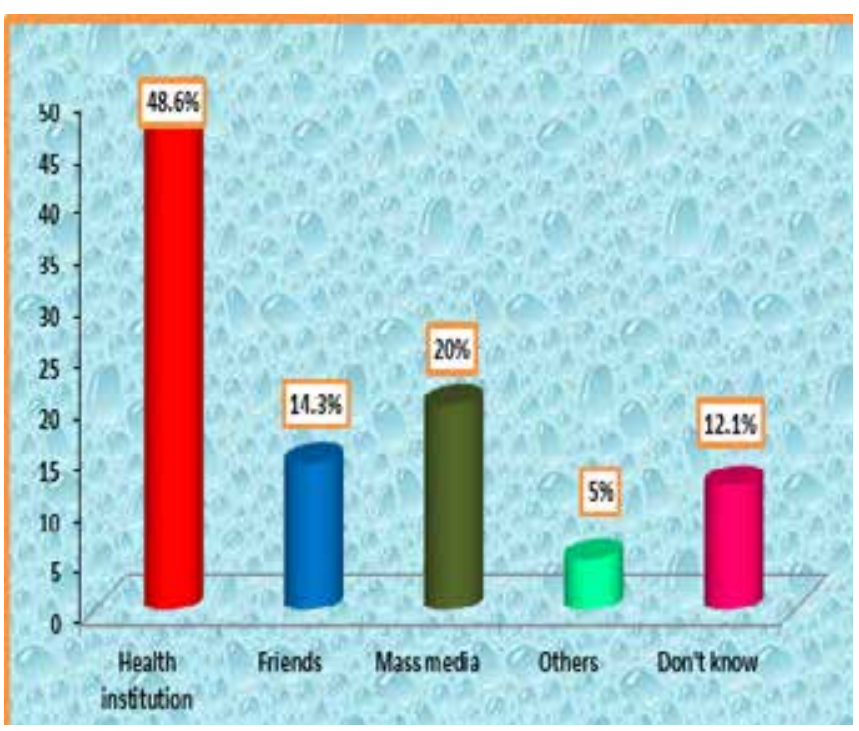

The above figure showed that out of 140 women, 123 (87.9\%) heard about exclusive breastfeeding and obtained their information 68 (48.6\%) from health institution, 20 (14.3\%) from friends, 28 (20\%) from mass media, seven (5\%) from others and 17 (12.1\%) women don't know about exclusive breastfeeding.

The result shows that among 140 women, 69 (49.3\%) had good knowledge and fair knowledge whereas only 
two $(1.4 \%)$ had poor knowledge with mean and standard deviation $(2.47 \pm 0.53)$.

Table 2: Attitude of study participants towards exclusive breastfeeding $(\mathrm{N}=140)$

\begin{tabular}{ccc}
\hline Items & Frequency & $\begin{array}{c}\text { Percentage } \\
(\%)\end{array}$ \\
\hline
\end{tabular}

Do you think that EBF is better than other artificial feeding?

- Yes

$87.1 \%$

- $\quad$ No

- Don't know

11

$7.9 \%$

Do you believe that the first milk (Colostrums) should be discarded?

- Yes

$46.4 \%$

- No

Do you agree that only EBF is enough for child up to 6 months?

- Agree

- Disagree

How did you feel when you give extra food other than breast milk to your child $<6$ months?

- Didn't feel comfort

- Comfortable with it

$45 \%$

Why you are not comfortable with extra feeding other than breast milk?

- Not sufficient to meet child's demand

- It's not necessary for child

- Complain of feeling pain

3

Do you agree that child less than 6 month who is exclusively breastfed is healthier than child who takes additional food?

\begin{tabular}{llcc} 
- & Yes & 100 & $71.4 \%$ \\
- & No & 8 & $5.7 \%$ \\
- & Don't know & 32 & $22.9 \%$ \\
\hline
\end{tabular}

EBF - Exclusive Breast Feeding

The result shows that out of 140 women, 122 (87.1\%) thought that EBF was better than other artificial feeding, $75(53.6 \%)$ believed that first milk should be discarded,
$108(77.1 \%)$ agreed that EBF is enough for child up to 6 months, 77 (55\%) didn't feel comfortable with extra feeding other than breast milk, 51 (36.4) stated that they were not comfortable because of insufficient amount to meet child's demand, 100 (71.4\%) agreed that child less than six months who is exclusively breastfed were healthier than child who took additional foods.

Table 3: Practice of study participants towards exclusive breast feeding $(\mathrm{N}=140)$

\begin{tabular}{lcc}
\hline \multicolumn{1}{c}{$\quad$ Items } & Frequency & $\begin{array}{c}\text { Percentage } \\
\text { (\%) }\end{array}$ \\
\hline $\begin{array}{l}\text { Have you breastfed your last } \\
\text { child? }\end{array}$ & & \\
- Yes & 139 & $99.3 \%$ \\
- No & 1 & $0.7 \%$ \\
$\begin{array}{l}\text { When did you start breast- } \\
\text { feeding after delivering your } \\
\text { last child? }\end{array}$ & & \\
- Within 1 hr & & \\
- Between 1 and 24 hrs & 43 & $59.3 \%$ \\
- $\quad$ After 24 hrs & 11 & $32.9 \%$ \\
$\begin{array}{l}\text { How frequently did you } \\
\text { breastfed your last child? }\end{array}$ & & $7.9 \%$ \\
- On demand & & \\
- $\quad$ Regularly & & \\
- $\quad$ Randomly & & \\
Have you given your last baby \\
$\begin{array}{l}\text { anything before initiating } \\
\text { breastfeeding? }\end{array}$
\end{tabular}

The result shows that out of 140 women, 139 (99.3\%) breastfed her last child, 83 (59.3\%) started breastfeeding 
within one hour after delivery, 77 (55\%) breastfed on demand of baby, 91 (65\%) had not given anything before initiating breastfeeding, 25 (17.9\%) had given plain water before breast milk after delivery, 107 (76.4\%) had given breast milk only starting from birth to six months of age.

\section{DISCUSSION}

The study shows that out of 140 women, 48 (34.3\%) belonged to 26 - 30 age group, 136 (97.14\%) were married, 109 (77.9\%) women followed Hindu caste, 67 (47.9\%) women belonged to Dalit group, 129 (92.1\%) women were housewife, $73(52.1 \%)$ women had taken primary education, $68(48.6 \%)$ had monthly income >20000, 116 (82.9\%) had $\leq 3$ children. 123 (87.9\%) women heard about exclusive breastfeeding and obtained their information 68 (48.6\%) from health institution, 20 (14.3\%) from friends, 28 (20\%) from mass media, seven (5\%) from others and 17 (12.1\%) women don't know about exclusive breastfeeding.

Similar study was conducted in Mizan Aman town, South West Ethopia to assess knowledge, attitude and practice towards breastfeeding mothers which showed that majority of $(68.5 \%)$ were between $20-30$ years, were married $(80.6 \%)^{11}$. Another study done in Aminu Kano Teaching Hospital, Nigeria to assess the knowledge, attitude and practice of exclusive breastfeeding among multigravid women attending antenatal clinic which showed that most of the respondents (57.6\%) were in the age group of $21-30$ years, $97.2 \%$ were married and 95.2\% knew about exclusive breastfeeding and obtained their information $74.4 \%$ from health care workers, 3.6\% from media and $17.2 \%$ from family/friends ${ }^{12}$.

Among 140 women, 69 (49.3\%) had good knowledge and fair knowledge whereas only two (1.4\%) had poor knowledge $(2.47 \pm 0.53, \mathrm{M} \pm \mathrm{SD})$.

Similar study was done on India to assess knowledge, attitudes and breastfeeding practices of postnatal mothers which showed that mothers had good knowledge on breast feeding $(12.05 \pm 1.74, \mathrm{M} \pm \mathrm{SD})^{13}$.

Regarding attitude 122 (87.1\%) thought that EBF was better than other artificial feeding, 75 (53.6\%) believed that first milk should be discarded, 108 (77.1\%) agreed that EBF is enough for child up to six months, 77 (55\%) didn't feel comfortable with extra feeding other than breast milk, 51 (36.4\%) stated that they were not comfortable because of insufficient amount to meet child's demand,
100 (71.4\%) agreed that child less than six months who is exclusively breastfed were healthier than child who took additional foods.

Similar study was conducted in Mizan Aman town, South West Ethopia to assess knowledge, attitude and practice towards breastfeeding mothers which showed that out of mothers, $205(73 \%)$ stated that EBF was better than artificial feeds, most mothers $281(89.5 \%)$ preferred to feed their children only breast milk, 59.3\% agreed that EBF is enough up to six months of age, $59.6 \%$ ( 187) did not feel comfortable when they gave extra foods other than the breast, and $(182 ; 58.0 \%)$ agreed that exclusively breastfed children are healthier than non-exclusively breastfed children ${ }^{11}$.

Another study done in Aminu Kano Teaching Hospital, Nigeria to assess the knowledge, attitude and practice of exclusive breastfeeding among multigravid women attending antenatal clinic which showed that majority (69.6\%) of the respondents agreed that breast milk alone is sufficient to the baby during the first six months of life and almost all (94.4\%) the respondents agreed that exclusive breastfeeding has benefits to the baby ${ }^{12}$.

The result shows that out of 140 women, 139 (99.3\%) breastfed her last child, 83 (59.3\%) started breastfeeding within one hour after delivery, 77 (55\%) breastfed on demand of baby, 91 (65\%) had not given anything before initiating breastfeeding, 25 (17.9\%) had given plain water before breast milk after delivery, 107 (76.4\%) had given breast milk only starting from birth to six months of age.

Similar study was done in BPKIHS, Dharan to assess the knowledge and actual practices of mothers regarding breastfeeding. The study showed that $41.5 \%$ had started breastfeeding less than one hour. Another study done in Aminu Kano Teaching Hospital, Nigeria to assess the knowledge, attitude and practice of exclusive breastfeeding among multigravid women attending antenatal clinic which showed that $47.2 \%$ exclusively breastfeeds for first six months of life ${ }^{14}$.

\section{REFERNECES}

1. WHO. Early initiation of breastfeeding: WHO, Geneva; 2010. Available from URL: http://www.who.int/ nutrition/topics/exclusive_breastfeeding/en/

2. WHO. Indicators for assessing infant and young child feeding practice part 3. WHO, Geneva; 2010. Available from URL: http://www.who.int/features/qa/21/en/ 
3. Butte NF, Lopez-Alarcon MG, Garza C: Nutrient adequacy breastfeeding for the term infant during the first six months of life. Geneva, Switzerland: world Health Organisation, 2002.

4. Exclusive breastfeeding. Give your infant the power to fight infections. Published: August 02, 2016. Available from URL: https://thehimalayantimes.com/health/ exclusive-breastfeeding/

5. Hanson LA. Immunobiology of human milk. 1st edition. Amarillo, Texas, USA; 2004.

6. Dorea JG. Breastfeeding is an essential complement to vaccination. Acta Paediatr. 2009; 98: 1244-1250.

7. WHO.10 facts on breastfeeding. August 2017. Available from URL: http://www.who.int/features/ factfiles/breastfeeding/en/

8. Black RE, Allen LH, Bhutta ZA, Caulfield LE, de Onis M, Ezzati M, Mathers C, Rivera J. Maternal and child undernutrition: Global and regional exposures and health consequences. Lancet. 2008; 371: 243-260.

9. Mohammad K, et al. Knowledge, attitude and practice of breastfeeding in the North of Jordan: A cross- sectional study. International Journal of Breastfeeding. 2006; 1:17, 1-6.

10. Gupta A. Protection, Promotion and Support of breastfeeding in South Asia, Nepal Pediatric Society and SAARC conference. 2002; 14-16 March: 1-4.

11. Tadele N, Habta F, Akmel D, Deges E. Knowledge, attitude and practice towards exclusive breastfeeding among lactating mothers in Mizan Aman town, SouthWestern Ethiopia: Descriptive cross-sectional study. International Breastfeeding Journal. 2016; 11: 3.

12. Aliyu A. Knowledge, Attitude and Practice of Exclusive Breasfeeding among Multigravid women attending antenatal clinic in Aminu Kano teaching Hospital. IOSR Journal of Nursing and Health Science. 2016; 5(6): 59-74.

13. Vijayalakshmi P, Susheela T, Mythili D. Knowledge, attitudes and breastfeeding practices of postnatal mothers: A cross sectional survey. International Journal of Health Science, 2015; 9(4): 364 - 374.

14. Chaudhary R, Shah T, Raja S. Knowledge and practice of mothers regarding breastfeeding: A hospital based study. Nepal Journal Online. 2011; 9(3) : 194- 200. 